\title{
Needs and Readiness Assessments
}

\section{Tools for promoting community-university engagement with Aboriginal communities}

\section{Fay Fletcher \\ Alicia Hibbert \\ Fiona Robertson}

\author{
Jodie Asselin \\ University of Alberta
}

Gateways: International Journal of Community Research and Engagement Vol 6 (2013): 131-49

(C) UTSePress and the authors

ISSN 1836-3393
Community-based participatory research (CBPR) is recognised by national funding organisations as the most appropriate, even the most desirable, approach to research involving marginalised communities (Canadian Institutes of Health Research 2008), establishing an expectation that researchers will engage communities in meaningful ways and as equal partners throughout the research process (Minkler \& Wallerstein 2003). As a result, there is increased acknowledgement by scholars of the importance of engaging those who can bring their own perspectives and understanding of community life to key issues (McCloskey et al. 2011). Israel et al. (1998) promote the use of CBPR methods in public health research, as they allow researchers to look at the social and environmental factors involved in health outcomes and to apply health knowledge in community settings. Our use of the term CBPR is derived from Israel et al. (1998) and refers to the participation of non-academic researchers (Métis Settlement members) in the process of co-creating knowledge, with both community and university partners contributing their individual strengths to improving community wellbeing.

In this article we discuss a CBPR project conducted in partnership with Buffalo Lake Métis Settlement (BLMS), an Aboriginal community in Alberta, Canada. In Canada, the term 'Aboriginal' is used to describe First Nations, Métis and Inuit peoples. This partnership explored community readiness to participate in the development and evaluation of a life skills and substance abuse prevention program, with a focus also on community needs. Through this partnership, community needs and readiness assessments were identified as critical components in overcoming the challenges of achieving engagement. Partnership development goals with BLMS included developing community ties and facilitating program ownership by the community. As individuals from BLMS expressed interest in developing life skills programs from the ground up, the researchers strove for relational accountability between the university and the community. A component of building this relationship was completing a needs and readiness assessment to foster the emergence of community 
priorities, inform the next steps of research design and program content development, and establish evaluation methods. In order to achieve these goals, the first two years of the research project were dedicated to building the partnership, with subsequent years devoted to developing life skills program content and evaluation measures. This article focuses on these first two years of engagement.

We believed that these early stages of working together would lay the foundation for successful, sustained engagement. In conducting needs and readiness assessments, it was our belief that relationship building would occur early in the research project and help the research team to overcome some of the challenges of Aboriginal community-university engagement in CBPR. Dempsey's (2010) article on the challenges to successful engagement prompted the following analysis of lessons learned from universitycommunity engagement. Among these challenges, the following were key:

-Ambiguity of community: how community specific is the approach?

-Campus/community divide: how are differences addressed and even used as tools in the partnership?

-Demand for community participation: how can the burden of participation on community members be reduced?

-Institutionalised practices: how do institutions (in this case, the university) create barriers for engagement?

Before discussing this in detail, we provide some brief information on Métis and the background to the research, followed by an overview from the literature on needs and readiness assessments, and in particular the nine stages consistently used to identify community readiness. These stages are measured across six key dimensions. We use these stages as a framework for examining the findings from the needs and readiness assessment we conducted with BLMS. Presenting our findings in this way allowed us to then explore whether or not the needs and readiness assessment process did help lay the foundation for a successful, ongoing engagement process. Dempsey's (2010) four points, listed above, offer some questions to help reflect on our success in the engagement process.

This article suggests that a needs and readiness assessment can be critical in reducing/responding to some of the above challenges, and it identifies a number of key ways in which this may occur. The time invested in needs and readiness assessments may allow the research team to discover difference both within and between communities, identifying strengths as well as areas of cultural ambiguity. This community-specific knowledge may allow research teams to identify areas where institutions create both opportunities and barriers to address the local context of the community. This article will show key learnings that will inform our ongoing partnership with BLMS and provide valuable insight for working with other Settlements in future. The challenges of 
Figure 1: Prevalence of diagnosed chronic conditions, by Aboriginal identity group, off-reserve population aged 20 or older, Canada, 2006/2007 (Statistics Canada 2006)
CBPR and community engagement can be mitigated by focusing on relationships; a needs and readiness assessment can provide a critical means for reducing associated challenges.

\section{BACKGROUND TO THE RESEARCH}

Buffalo Lake Métis Settlement, located $180 \mathrm{~km}$ from the nearest major city, shares a history of colonisation and marginalisation with other Aboriginal communities in Canada, experiencing disproportionate rates of social, health and economic burdens compared to the non-Aboriginal population in Canada (Martens et al. 2011).

The Métis are one of the three constitutionally recognised Aboriginal groups in Canada (McNab 2005). Despite this, the Métis are overlooked within Aboriginal health research and addressed primarily within pan-Aboriginal studies (Driben 1985; Findlay 2011; Lamouche 2002; Martens et al. 2011; Tjepkema et al. 2011; Younge 2003). As of 2006, the Aboriginal population in Canada was 1172 790, representing 3.7 per cent of the total population; of that total, the Métis number 389 785, and are the fastest growing Aboriginal group in Canada (Gionet 2009). Despite comprising one-third of Canada's Aboriginal peoples, the health disparities between the Métis and other Canadians remain unaddressed (Martens et al. 2011). Figure 1 shows the extent of these disparities.

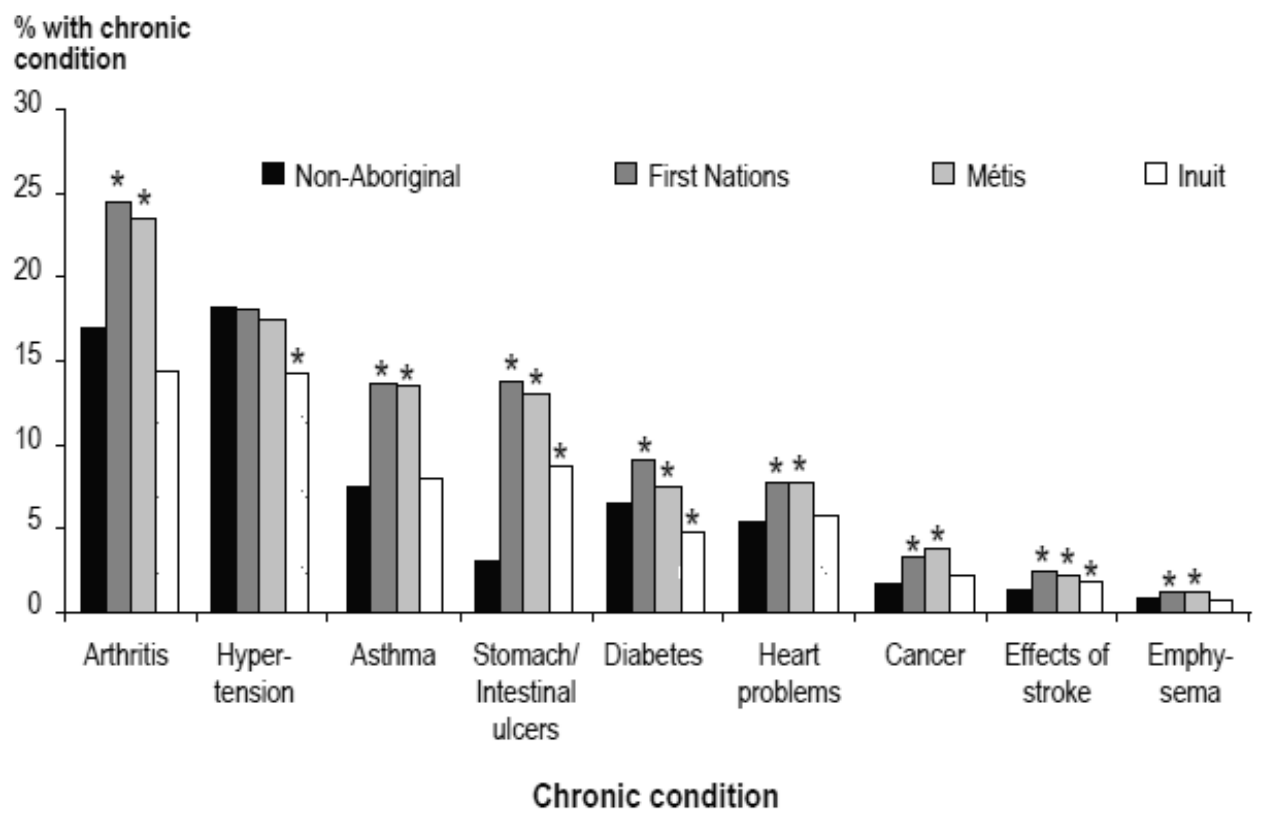

Chartrand (2011) has argued that Métis face different challenges from those of the general Canadian population, including First Nations and Inuit communities and, along with Dyck (2009), has advocated for health research that is culturally grounded within Métis communities to address these differences. Fortunately, Alberta Health Services, the provincial health-care provider in Alberta, saw the need to work with a Métis Settlement to produce a needs and readiness assessment and funded this work as part of a larger project adapting and developing life skills programs for children in First Nations communities. 
The impetus for the work with the Métis community also grew out of an earlier successful collaboration between researchers from the University of Alberta and several First Nations communities in Alberta on the delivery and evaluation of an evidence-based, culturally adapted substance abuse and violence prevention program (Baydala et al. 2009, 2011a; Baydala, Worrell \& Fletcher 2011b) based on the Botvin Life Skills Program (Botvin et al. 1989, 2003; Griffin et al. 2003). Within these studies, a multi-method approach consisting of quantitative surveys and qualitative focus groups and interviews showed positive impacts on children's refusal skills, self-belief and knowledge of the negative effects of drug and alcohol use. These results provided the evidence needed to secure research funds for this assessment of the need for and readiness of one Métis Settlement to develop a similar program for their children and youth. Ethical approval was granted by the University of Alberta Research Ethics Board on 6 June 2010.

A Métis colleague, who had a pre-existing relationship with BLMS, introduced the principal investigator to BLMS Settlement Council, the Settlement's local governing body. Council members were asked if they were interested in a potential research partnership with the University of Alberta to assess the community's need for a youth life skills program. During that meeting, council members expressed their ardent belief in the need for life skills and substance abuse prevention training across all ages in their community, but especially among youth. The Council's unanimous agreement that such programs were necessary for their members served as the first sign of the community's readiness. On 22 June 2010, the Council passed a motion to support a community needs and readiness assessment. Two community members were then recruited as paid research assistants whose responsibilities would include planning and conducting focus groups with community representatives.

\section{METHODOLOGY OF THE PROJECT}

Evaluating community readiness, defined here as the degree to which a community is prepared to take action on an issue (Donnermeyer et al. 1997), helps researchers understand processes of community change and develop strategies for addressing issues (Plested, Edwards \& Jumper-Thurman 2006). In turn, this encourages communities to define their own issues and strategies, builds cooperation between stakeholders and participants, encourages participation, and increases capacity for intervention. A community readiness assessment is aligned with CBPR principles that promote building on existing strengths and resources within the community (Israel et al. 1998); for the readiness assessment at Buffalo Lake Métis Settlement, community assets were preidentified by a small number of community members, then further expanded and ranked in participatory focus group activities with a larger number of participants. Research has shown that community members must agree that a problem or issue is locally 
important for a prevention strategy to succeed (Andersson \& Nahwegahbow 2010; Jumper-Thurman, Vermon \& Plested 2007; Krieg, Martz \& McCallum 2007). Furthermore, programs put in place to solve community problems are more likely to be successful if they fit local norms and encourage local participation (Edwards et al. 2000). Therefore, community members were given the opportunity to define priority areas to be addressed in a life skills program through multiple levels of qualitative data collection with embedded feedback loops. Through focus groups, employing community members as key project staff, frequent community meetings, and providing updates and discussion space with community leaders, community members were able to ensure that the developing program would fit their needs, while also giving researchers a more in-depth understanding of the community.

The community readiness approach recognises that programs should be tailored to fit the realities of individual communities. Nine stages of community readiness are consistently used throughout the literature (Donnermeyer et al. 1997; JumperThurman 2000; Oetting et al. 2001; Plested, Edwards \& JumperThurman 2006). Stage 1 reflects a low level of readiness and Stage 9 reflects a high level of readiness:

1 community tolerance/no awareness

2 denial

3 vague awareness

4 pre-planning

5 preparation

6 initiation

7 institutionalisation

8 confirmation/expansion

9 professionalisation.

Community readiness is determined by assessing each stage across six key dimensions (Oetting et al. 2001; Plested, Edwards \& Jumper-Thurman 2006):

1 existing efforts to address issues

2 community knowledge of these efforts

3 community leadership

4 community knowledge about the issue

5 resources (funding) related to the issue

6 community climate.

In contrast to measures we have used in previous Aboriginal research projects (Fletcher, McKennitt \& Baydala 2008), the stages and dimensions of readiness proved appropriate as we proceeded with the project. However, after determining that survey 
instruments were not the most effective means of gathering needs and readiness information from the community, we adapted our methods to include participatory focus group activities.

As a community-grounded project is the most effective approach to addressing health needs (Andersson \& Nahwegahbow 2010; Jumper-Thurman 2000; Krieg, Martz \& McCallum 2007), priority was given to community members' participation in every possible stage of project development. Although the issue (drug, alcohol and bullying prevention) was pre-determined for this project, community members participated in and shared community priorities through the needs and readiness assessments already described, as well as program development, implementation and evaluation. Additionally, we looked to the needs and readiness assessments to develop relationships so that community members could propose meaningful initiatives and solutions. The community needs and readiness assessments completed in 2010-2011 represent a form of pre-engagement in the discovery, exploration and trial alliance phases, as outlined by Campbell-Voytal (2010), allowing for tentative collaboration with an 'opportunity to observe, listen, and try out a tentative alliance' (p. 157).

\section{Data Collection}

Six focus groups, with a total of 21 participants, were held with BLMS community members to assess the perceived relevance of life skills topics; these topics were gathered from similar programs with First Nations communities (Baydala et al. 2009). The breakdown for the focus groups included two youth focus groups (14-24 years of age), two seniors/elders groups (60+) and two with adults (25+) representing parents and service providers from health and social services. The focus groups allowed participants to suggest additional topics for life skills education. Two community members were hired to plan the focus groups and recruit participants.

Recruitment, which was challenging in this remote rural setting, was achieved through word of mouth and advertisements in the community newsletter.

Methods consisted of a combination of recorded and nonrecorded focus groups. The original questions, from Plested, Edwards and Jumper-Thurman (2006), were adapted to compensate for lower reading comprehension levels and to break down the typical formality employed in survey and focus group language. In the researchers' experience, formal academic language is generally inappropriate when used in discussions with non-academic focus group participants; maintaining colloquial language creates a more equitable environment. The following questions were presented to individuals in a survey format at the initial focus groups to focus later discussion:

1 What are the top 2 or 3 most important issues facing Buffalo Lake? 
2 How much of a concern is substance abuse and violence in your community? (Please circle your answer from 1-10, with 1 being 'not at all' and 10 being 'a very great concern').

3 How much of a concern is substance abuse and violence to the leadership in your community? (Please circle your answer from 1-10, with 1 being 'not at all' and 10 being 'a very great concern').

4 How much of a concern is addressing substance abuse and violence through a prevention intervention to the leadership in your community? (Please circle your answer from 1-10, with 1 being 'not at all' and 10 being 'a very great concern').

5 What is the level of expertise and training among those working on substance abuse and violence prevention in the community? (Please circle your answer from 1-10, with 1 being 'very low' and 10 being 'very good').

6 Given these efforts to address substance abuse and violence prevention, to what extent are other community members aware of these efforts and available resources? (Please circle your answer from 1-10, with 1 being 'not at all' and 10 being 'very aware').

During the first focus group it became immediately apparent to researchers that the survey and traditional focus group setting was not producing effective results. Participants were reticent and mostly uncommunicative. In order to promote discussion, two proprietary interactive tools - the Target Activity and ThermoScale (Fletcher et al. 2013), described below - were introduced, with guiding questions to explore perceived community need and readiness to partner in a community-university research project. Survey questions were also adapted into open discussion questions, so that results would still reflect the community needs and readiness assessment concepts, but would be achieved in a manner more acceptable to participants. Based on our experience, the research team determined that a consensus-based approach would be more effective in fostering in-depth discussion among participants about perceived needs and readiness. This would in turn help to enrich our understanding of the community. Data collection and findings are presented briefly below.

The Target Activity (Fletcher et al. 2013) was used to explore whether community members felt that a life skills program was needed. This activity involved a large poster of a target with three concentric rings. Post-it notes were placed around the outside edges of the poster, featuring pre-written topics derived from the current literature (Botvin et al. 2003) and recent research in First Nations communities on drug and alcohol resistance (Baydala et al. 2009). Focus group participants were asked to come to a consensus on the degree to which a variety of resistance skills and knowledge areas might contribute to community wellness. The activity itself was developed by the authors as a pragmatic approach to encourage 
discussion and had been trialled successfully in previous studies (Fletcher et al. 2013). Each skill/knowledge was labelled critical, important, or noteworthy. Participants were also asked to add their own topics and to indicate at what age they thought such a skill should be introduced. Topics of critical importance included alcohol, bullying, dealing with anger, drug use, peer pressure, and violence. Topics considered important to address included dealing with conflict, gambling, gender roles, grieving, self-esteem/selfimage, smoking/tobacco, and stress. Noteworthy topics included advertising, assertiveness and communication skills, dealing with anxiety, decision-making, kinship, media, neighbourliness, and spirituality. Community members in the focus group specifically introduced the topics of gang awareness, gambling, gender roles, kinship, neighbourliness, and spirituality.

The ThermoScale (Fletcher et al. 2013), adapted from McCabe and Horsley (2008), was used to explore community readiness and to help the researchers understand the community from the perspective of its members. Two community members working on the project first reviewed the tool and the pre-determined community assets. Through consensus, participants placed community assets on a scale from cold (weak community asset) to hot (strong community asset) to demonstrate the character of their community. The list of assets originated from community readiness literature (Donnermeyer et al. 1997; Jumper-Thurman 2000; Oetting et al. 2001; Plested, Edwards \& Jumper-Thurman 2006). Participants were given the opportunity to identify additional assets, allowing them to express community values that the researchers had not anticipated. In total, 39 assets were discussed and placed on the scale. Results from both activities led to the needs and readiness assessments.

The six dimensions of community readiness focused the analysis of the focus group notes, activity photos and transcripts: 1 Existing efforts to address the issue. Although the issue of youth drug use and bullying was defined by existing funding and supported by a motion from BLMS Council, there were no existing programs in the community supporting life skills development for children, youth, or adults. Focus group participants supported the proposal to develop a program that would have a positive impact on reducing substance abuse and violence, with results focusing on the need to impact children around the age of seven.

2 Community knowledge of these efforts. Participants shared that there were no existing life skills or substance abuse/violence prevention programs in the community. Earlier programs for adults had not been particularly successful or relevant to the local context. The absence of relevant life skills programs impacted the course of further program development by demonstrating the need for a ground-up, community-driven approach and the necessity to base program development upon Métis-specific content. 
3 Community leadership. BLMS Council members were strongly supportive of a project that would respond to the issues of drug abuse and bullying. Local resources were made available to the research team, including community space for focus groups, and key community members were identified as enthusiastic contributors.

4 Community knowledge about the issue. Participants were well aware of existing issues of drug and alcohol abuse and violence, were concerned about their impacts on community wellbeing, and recognised that action should be taken to address these issues. Gang violence had not been identified as a local issue by the research team prior to the focus groups.

5 Funding resources related to the issue. Although there were no available funding sources in the local community, the community was willing to provide resources through inkind support, including infrastructure to support full-time employment in the community for subsequent stages of the project. Community members were very knowledgeable about available resources in their community.

6 Community climate. There was a lack of consensus among the participants about the community climate, with the greatest divide between youth and senior participants. Youth were far more likely than seniors to speak positively about community resources (including the services of health-care workers, mentors, volunteers and Royal Canadian Mounted Police) and the community's overall sense of identity and feeling of unity.

\section{FINDINGS AND DISCUSSION}

Findings from the needs and readiness assessment were used to determine the design of the next phase of the research project, including program content and measures of community impact and individual developmental strengths. Dempsey's (2010) critique of community engagement helped us realise the extent to which needs and readiness assessment activities contributed to our ability to resolve some of the difficulties of BLMS community engagement. These potential areas of difficulty included: 1) the ambiguity of community, 2) the campus/community divide, 3) the demand for community participation, and 4) institutionalised practices (in particular, university policies and practices). This experience corroborates Dempsey's claim that building authentic relationships is critical to community-university engagement. To exemplify this, each section that follows covers one of these four areas of potential difficulty in community-university engagement, closing with a key learning.

\section{The Ambiguity of Community}

Dempsey (2010) notes that there is a tendency in research to downplay the complexity of communities, by treating communities as homogeneous entities. In the process of completing the 
needs and readiness assessments, we realised that, despite acknowledgement of diversity among the First Nations in Canada, the cultural distinctions - spiritual beliefs, ceremony, language, food practices - between Métis and First Nations peoples are often overlooked. While the diversity among First Nations peoples in Canada can be compared to the diversity among Native Americans in the United States, there is no such comparison for Métis people's unique history and culture. Métis Settlement members are further distinct from the Métis Nation of Canada and pronounced cultural differences also exist between Settlements. For example, the assumption that an Aboriginal language is necessarily related to Aboriginal cultural identity was shattered by BLMS as participants ranked the languages traditionally associated with Métis culture - French, Cree and Michif - as unimportant or weak community assets.

We propose that the current use of the term 'Aboriginal' in Canada tends to homogenise the experience of three very distinct groups: First Nations, Métis, and Inuit. Years of research with First Nations contributed to our own application of panAboriginal assumptions to Métis during the needs and readiness assessment phase. For instance, the anticipated role of Elders and the concept of spirituality were two sensitive, yet extremely important community dynamics to understand in order to promote meaningful engagement.

While working with First Nations, we learned to make participation and guidance from formal Elders a priority in our work. Although we assumed the same of our Métis colleagues, we learned through the assessment process, as well as at Council meetings, that approval to proceed rested with the Settlement Council. To assume an Elder-first approach to community involvement was to incorrectly allow pan-Aboriginal assumptions to inform our work with Métis. Contrary to the normative Elder role in First Nations, Elder authority is not formalised at BLMS. At BLMS, an elder is a respected senior - it does not denote the proper noun, 'Elder', as is used in First Nations communities. When asked about the need for elder involvement, none of our community colleagues expressed concern about the absence of a committed elder working on the project. We addressed this issue directly with the BLMS local advisory committee, which was initiated after the needs and readiness assessment phase, and were informed that the community has seniors, who undoubtedly hold community cultural knowledge and are referred to as elders, rather than Elders in the First Nations tradition.

In further contrast to our expectations, the focus groups identified BLMS as predominantly Catholic and almost exclusively Christian. Preconceived ideas of what program content might look like, based on First Nations spirituality, were subsequently revised to reflect respect for diverse beliefs and values, rather than traditional teachings. Another historically and contemporarily significant Métis practice that the researchers did not anticipate included fiddling, traditionally associated with the dance 
style known as the Métis jig. Artistic and ceremonial practices considered significant to First Nations, such as carving, drumming and smudging, were not relevant to BLMS.

Key learning: our needs and readiness assessment offered a process for redefining community in terms of its heterogeneity. As suggested by Dempsey (2010, p. 365), 'Acknowledgement of diversity of community opens up understandings of the politics involved with identifying and representing community interests'. Had we not spent the time working with community members to complete the needs and readiness assessments, our actions would very likely have reinforced a pan-Aboriginal approach that would have, at the least, compromised our research relationships and goals, and at worst, made impossible any chance of a community-university partnership. The process of doing the needs and readiness assessments heightened our awareness of community ambiguity and our capacity to respond appropriately, with openness and respect, to what may be perceived as cultural ambiguity.

\section{The Campus/Community Divide}

Dempsey (2010, p. 364) stated, 'Universities - as complex organizations - are embedded within various over-lapping historical, political, and economic relationships with their surrounding communities', and that the imaginary divide created between the university and communities (downplaying the fact that these spheres overlap) threatens engagement. It is through proactive discussions that acknowledge participants' understanding of our ancestors' place in a shared history, and our ongoing responsibility to social justice (Fletcher 2013), that we overcome the potential threat of the campus/community divide. Our individual differences, including age, gender, religion, culture and socioeconomic standing, are embedded within our institutional membership and history and are additional potential threats to community engagement. These differences are minimised by accentuating shared experiences and goals and building upon the strengths that are made possible by difference (Dempsey 2010, p. 364).

Métis Settlements have pre-determined rules for membership. Despite Dempsey's (2010) comment on the positive potential of researchers and community members belonging to the same community, there was no way that research team members, in this particular case, could be members of the Métis Settlement. In fact, the rules that set membership in our communities - including Settlement and University - necessitate building the research partnership across communities. However, in contrast to Dempsey's point, we took steps to acknowledge differences and believe that doing so contributed to our ability to achieve shared goals: some individuals had knowledge of the community, including its political milieu, history and sense of local culture, while other individuals had expertise in securing funding, working through institutional processes, providing administrative leadership and 
facilitating research. Making transparent our differences and our shared commitment to improving community wellness allowed for many points of convergence between team members. We believe that this approach to community-university engagement, even though it may have been apparent and intentional only on the part of the university members, was critical to success and for that reason deserves attention in this reflection. Community engagement was shaped by educational and research experiences that very intentionally attended to differences and similarities.

Kanpol (1995) writes of an educational system that requires educators and students to join in unity in mutual learning and teaching to find 'terrains of similarity of solidarity'. In our case, university-based team members were aware of the history of First Nations, Métis and Inuit peoples in Canada. We acknowledged that inequities between Aboriginal and non-Aboriginal groups stem from the long-term impacts of colonial policies and legislation, and that we share responsibility for achieving equity. Through this approach, participants engaged in critical and ethical reflection about what it meant to bring a wide variety of cultures into dialogue with each other, unifying without losing touch with individual differences.

Key learning: Dempsey (2010) suggested that, to acknowledge difference, we discuss our individual goals, whether personal or professional, and attempt to describe the accountabilities of each partner. Our needs and readiness assessment amplified our attention to this and reinforced our commitment to attend to each other's strengths. In taking a strengths-based approach to project management, the research team was inspired to complete and share the results of Rath's (2012) StrengthsFinder test as a community-university research team. The StrengthsFinder test served as a means to discuss our preferred roles and responsibilities in the project as well as our accountability to various aspects of the project. We explored our strengths as individuals in order to view our differences positively. As a team, we minimised the potential community-university gap by valuing individual strengths and taking these into consideration at each new stage of project planning.

\section{The Demand for Community Participation}

The third challenge presented by Dempsey (2010) highlights the burden placed on community when, in the absence of adequate funding, research projects rely on volunteers and in-kind support from communities. Israel et al. (1998) promotes the concept of facilitating collaboration between university team members and community members in all phases of the research. Having worked with and been mentored in the non-profit sector, the principle investigator knew the importance of contributing financially to the 'bottom line' to honour the efforts needed for collaboration. As a result, whenever possible, priorities in the funding allocation included money to pay employees and rent space in the community 
or, at the very least, honoraria to compensate them for their time and expertise.

Office space was rented at BLMS for the two research assistants hired to recruit a cross-section of community members to participate in the needs and readiness assessment focus groups. These research assistants arranged for the research team members to attend the monthly luncheon at the Community Seniors Centre, and participated in the development of the resources for the program. This approach created employment opportunities and contributed to infrastructure costs, thus representing a fair exchange between university and community. These actions underlined the value that was being placed on community knowledge and commitment.

In addition, university-based employees took on as many administrative and logistical responsibilities as possible, serving as the 'backbone' organisation between the broader university structure and the Settlement. A backbone organisation is defined as a structure that serves to tie together various organisations/ units in collective impact initiatives (Hanleybrown, Kania \& Kramer 2012); it is the supportive infrastructure to collaboration:

Backbone organizations serve six essential functions: providing overall strategic direction, facilitating dialogue between partners, managing data collection and analysis, handling communications, coordinating community outreach, and mobilizing funding (Hanleybrown, Kania \& Kramer 2012).

In our team, the backbone organisation consisted of university-based employees who performed both research and administrative roles. For example, university-based staff filled out personal expense reimbursement forms, informed community staff of their employee union rights, interpreted all university policies and procedures that would otherwise prove difficult to navigate, prepared and submitted all contracts and appointments, reconciled grant funds, and negotiated any HR or Finance-related issues of community staff with university units. We were able to structure our project in this way because our funders saw benefit in intervention over the long-term.

Key learning: While undertaking the needs and readiness assessment, we learned that there was a small but skilled group of people in the community and came to understand what it would take to support these people in ways that would make the demands on their time manageable while also meeting our research obligations. The result was a project management approach to research that facilitated broad thinking about possible funding sources that would allow us to align with, and provide financial support for, community and human resource development. In other words, research project management, resources, skills and strategies combined with the intent of alleviating the burden on the community. 


\section{Institutionalised Practices}

Finally, institutional practices, such as university and funding agency policies and procedures, including research ethics board criteria, have the potential to create significant barriers to positive community-university engagement (Israel et al. 2001).

The emphasis on obtaining written consent in the Canadian Institutes of Health Research guidelines (Canadian Institutes of Health Research 2008), which in turn becomes the basis for review by institutional boards in Canada, as per the experience of one of the authors' participation on an ethics review board, presents a potential barrier to engagement that could be avoided through oral consent or acceptance of consent by kin (Baydala et al. 2011a, p. 105). First Nations' Elders, through earlier research projects, taught us that seeking written consent is not always appropriate. The following example focuses on why and how institutional barriers need to be overcome in the ethics process.

Elders in a First Nations community accepted a tobacco offering to participate in a research project - implying a sacred commitment - and were later asked for further consent. As tobacco had already been offered and accepted, the additional consent requests made the Elders feel their integrity was being questioned (Baydala et al. 2013). In this case, institutional ethics policies imposed practices that were contradictory to community or cultural ethics. 'When traditional protocol has been offered and accepted by Elders, asking for written consent was interpreted as a lack of acceptance for the legitimacy of community protocol and is disrespectful of the Elders personal intent' (Baydala et al. 2013, p. 13). The academic team could not continue within the confines of the institutional ethics policies to build meaningful partnerships with the community's Elders, so the team worked with the research ethics board to create a meaningful and more appropriate consent process. This experience informed the research team's approach from the outset of the project with BLMS. A preference for oral consent and allowing for assent by minors, however, remain issues specific to conducting research with this community.

Based on our experience, major research grants such as the Tri-Council funding programs in Canada (Canadian Institutes of Health Research, Social Sciences and Humanities Research Council, and the Natural Sciences and Engineering Research Council of Canada) present barriers to community engagement by their policies for allowable expenses. For example, community office set-up is not typically an allowable expense under their program guidelines since all associated expenses - equipment, rental fees, janitorial services - constitute facility costs, which are considered overhead that should be provided by the institution (Natural Sciences and Engineering Research Council of Canada 2013). The institution, on the other hand, does not support satellite offices in rural communities by providing equipment and janitorial and repair services in a location hours away from the university campus. Likewise, in order to conduct CBPR research, computer 
software and financial management training must often be provided to both university and community partners. Israel et al. (2001) discuss the critical importance of professional development to a CBPR project as both community and university partners often must fulfil varied roles, from program administrator to community promoter, from project manager to public speaker, and from writer to research assistant. Again, these professional development costs are typically not eligible in a standard research grant and must, at minimum, use project resources to apply for special training grants (Natural Sciences and Engineering Research Council of Canada 2013). The institution offers such specialty training, at a cost, to research personnel.

In contrast, project funding through the Alberta Health Services Safe Communities Innovation Program allowed us to incur expenses critical to both project set-up and relationship building that contributed directly to community engagement. Eligible expenses included the remote office set-up (purchasing desks, computers and other equipment and paying to move these items to BLMS), salaries for community members, mileage for travel to the communities, refreshments provided for community members at meetings and focus groups, mobile phone costs for staff accessing the internet and text messaging while working offsite, and gifts of thanks to key community members. Knowledge mobilisation within the community was also improved through our ability to pay for a custom project website with a simple design aimed at disseminating project information within the community and the university. Since the completion of the needs and readiness assessment, project funds have also provided t-shirts and backpacks for child participants of our summer camp, gymnasium supplies for the BLMS Recreation Centre aimed at younger children, and team apparel that ensures program facilitators, volunteers and program staff stand out and are recognised in the community. These types of expenses, while not direct research expenses, provide concrete ways to demonstrate the commitment made to and by the community as a whole and advance relationship building within the community.

Key learning: There are institutional policies in university and major funding organisations that require ongoing commitment to education and continual effort to reform these policies. Given the opportunity, research ethics boards and funders seem willing to respond to the unique needs and conditions of ethics and engagement with First Nations, Métis and Inuit peoples. Changes in policy and practice are a requirement of ethical engagement. Although policies and practices are responding to the expectations of community-based research and engagement, persistence and commitment are required to extend discussions of ethics beyond research to community-university engagement.

\section{CONCLUSION}

We have shared our reflections on the community-specific challenges that were encountered in developing a research 
partnership with members of Buffalo Lake Métis Settlement in Canada. This work was prompted, supported and again challenged by Dempsey's (2010) critiques of the ambiguity of community, the campus/community divide and the individual differences (including culture, socioeconomic standing, gender, age) that can be present in a research partnership, the burden of participation on community members and the barriers to engagement arising out of institutional policies and procedures. In retrospect, the two years that were spent completing a needs and readiness assessment were vital to our ongoing engagement with the BMLS community and our subsequent research program. This activity fostered engagement between university and community partners and led to unanticipated effects on our research goals as we continue to strive to understand the unique context of this community. In this process, we were reminded again of the importance of questioning pan-Aboriginal assumptions and approaches when working with First Nations, Métis, or Inuit communities. Regardless of how many communities or how long our involvement as academic researchers, the uniqueness of each and every community and every initiative deserves the time and respect that was accorded through the process of completing this assessment.

Through this process of reflection, we were also reminded of the ongoing divide between community and university partners. Open and honest discussions about drug and alcohol use, gambling, violence and bullying in the community have allowed us to continually acknowledge and incorporate unique experiences, education and expertise. We developed greater insight into the capacity and readiness of the community to partner for research purposes as a result of the needs and readiness assessment. We were able to avoid placing an unfair burden on community partners. To reduce the potential strain of a research partnership on the community, our team centralised administrative and logistical responsibility with university-based employees, who acted as a backbone organisation in the research partnership. Finally, we learned first-hand that effective partnerships with Aboriginal communities may require pushing institutional research ethics boundaries in order to best serve the community, rather than simply avoiding risk for the university.

At the outset, when we were first introduced to BLMS Council and held focus groups with community representatives, our goal was to determine whether BLMS felt there was a need for a youth life skills program and whether they were ready for a research partnership with the university. By the end of the needs and readiness assessment, BLMS community partners and university partners shared the goal of creating a life skills program for children that would be relevant, culturally appropriate and community specific. Our ongoing relationship, subsequent approvals by BLMS Council and the development of a program that has since been delivered by community members represent 
successful community engagement. It is our opinion that this success is grounded in the needs and readiness assessment activities.

\section{REFERENCES}

Andersson, N \& Nahwegahbow, A 2010, 'Family violence and the need for prevention research in First Nations, Inuit, and Métis communities', Pimatisiwin: A Journal of Indigenous and Aboriginal Community Health, vol. 8, no. 2, p. 9.

Baydala, L, Worrell, S, Fletcher, F, Letendre, S, Letendre, L \& Ruttan, L 2013, 'Making a place of respect: Lessons learned in carrying out consent protocol with First Nations Elders', Progress in Community Health Partnerships: Research, Education and Action, vol. 7, no. 2, p. 135.

Baydala, L, Letendre, S, Ruttan, L, Worrell, S, Fletcher, F, Letendre, L \& Schramm, T, 2011a, "Why do I need to sign it?" Child assent in schoolbased prevention research in a First Nation community', First Peoples Child \& Family Review, vol. 6, no. 1, p. 99.

Baydala, L, Worrell, S \& Fletcher, F 2011b, 'FASD: A preconception prevention initiative', in E Riley, S Clarren, J Weinberg \& E Jonsson (eds), Fetal Alcohol Spectrum Disorder: Management and policy perspectives of FASD, Wiley-Blackwell, Weinheim, Germany, pp. 151-60.

Baydala, L, Sewlal, B, Rasmussen, C, Alexis, K, Fletcher, F, Letendre, L, Odishaw, J, Kennedy, M, \& Kootenay, B 2009, 'A culturally adapted drug and alcohol abuse prevention program for Aboriginal children and youth', Progress in Community Health Partnerships: Research, Education and Action, vol. 3, no. 1, p. 37.

Botvin, G, Dusenbury, L, Baker, E, James-Ortiz, S \& Kerner, J 1989, 'A skills training approach to smoking prevention among Hispanic youth', Journal of Behavioral Medicine, vol. 12, no. 3, p. 279.

Botvin, G, Griffin, K, Paul, E \& Macaulay, A 2003, 'Preventing tobacco and alcohol use among elementary school students through LifeSkills training', Journal of Child \& Adolescent Substance Abuse, vol. 12, no. 4, p. 1.

Campbell-Voytal, K 2010, 'Phases of "pre-engagement" capacity building: Discovery, exploration, and trial alliance', Progress in Community Health Partnerships: Research, Education, and Action, vol. 4, no. 2, p. 155.

Canadian Institutes of Health Research 2008, CIHR Guidelines for Health Research Involving Aboriginal People, viewed 28 August 2013, www.medicine. usask.ca/family/research/resources-for-research/ethics/ethics aboriginal guidelines metis e.pdf.

Chartrand, L 2011, Maskikiwenow: The Métis right to health under the Constitution of Canada and under selected international human rights obligations, National Aboriginal Health Organization, Ottawa, ON.

Dempsey, S 2010, 'Critiquing community engagement', Management Communication Quarterly, vol. 24, no. 3, p. 359.

Donnermeyer, J, Plested, B, Edwards, R, Oetting, G \& Littlethunder, L 1997, 'Community readiness and prevention programs', Journal of the Community Development Society, vol. 28, no. 1, p. 65.

Driben, P 1985, We are Métis: The ethnography of a halfbreed community in Northern Alberta, AMS Press, New York.

Dyck, M 2009, Social determinants of Métis health, National Aboriginal Health Organization, Ottawa, ON. 
Edwards, R, Jumper-Thurman, P, Plested, B, Oetting, E \& Swanson L 2000, 'Community readiness: Research to practice', Journal of Community Psychology, vol. 28, no. 3, p. 291.

Findlay, L 2011, Physical activity among First Nations people off reserve, Métis and Inuit: Health report, March, Statistics Canada, Ottawa, ON. Fletcher, F 2013, 'Little stories of social justice: Lessons I learned from immigrant women and First Nations people', in L Shultz \& T Kajner (eds), Education and the political project of engagement and disengagement, Sense Publishers, Boston, MA, pp. 89-105.

Fletcher, F, Baydala, L, Hibbert, A \& Robertson, F 2013, Interactive focus group tools, CES4Health.info, viewed July 2013, http://ces4health.info/ find-products/view-product.aspx?code=W64JY7FS.

Fletcher, F, McKennitt, D \& Baydala, L 2008, 'Community capacity building: An Aboriginal exploratory case study', Pimatisiwin: A Journal of Indigenous and Aboriginal Community Health, vol. 5, no. 2, p. 9.

Gionet, L 2009, Métis in Canada: Selected findings of the 2006 Census, Statistics Canada, Ottawa, ON.

Government of Canada 2013, 'Chapter 9: Research involving First Nations, Métis and Inuit peoples of Canada', Tri-Council Policy Statement: Ethical conduct for research involving humans, 2nd edn, viewed 6 August 2013, www.ethics.gc.ca/eng/policy-politique/initiatives/tcps2-eptc2/ chapter9-chapitre9/.

Griffin, K, Botvin, G, Nichols, T \& Doyle, M 2003, 'Effectiveness of a universal drug abuse prevention approach for youth at high risk for substance use initiation', Preventive Medicine, vol. 36, p. 1.

Hanleybrown, F, Kania, J \& Kramer, M 2012, 'Channeling change: Making collective impact work', Stanford Social Innovation Review, viewed February 2013, www.ssireview.org/blog/entry/channeling change making collective impact work?cpgn=WP\%20DL\%20-\%20 Channeling\%20Change.

Israel, B, Schulz, A, Parker, E \& Becker, A 2001, 'Community-based participatory research: Policy recommendations for promoting a partnership approach in health research', Education for Health, vol. 14, no. 2, p. 182 .

Israel, B, Schulz, A, Parker, E \& Becker, A 1998, 'Review of communitybased research: Assessing partnership approaches to improve public health', Annual Review of Public Health, vol. 19, p. 173.

Jumper-Thurman, P 2000, 'Community readiness: A promising model for community healing', in D Bigfoot (ed.), Native American Topic Specific Monograph Series, U.S. Department of Justice, The University of Oklahoma Health Sciences Center.

Jumper-Thurman, P, Vermon, I \& Plested, B 2007, 'Advancing HIV/AIDS prevention among American Indians through capacity building and the community readiness model', Journal of Public Health Management Practice, January suppl., p. 49s.

Kanpol, B 1995, 'Multiculturalism and empathy: A border pedagogy of solidarity', in B Kanpol \& P McLaren (eds), Multiculturalism: Uncommon voices in a common struggle, Bergin and Garvey, Westport, CT, pp. 177-95.

Krieg, B, Martz, D \& McCallum, L 2007, Access to health services for elderly Métis women in Buffalo Narrows, Saskatchewan, Prairie Women's Health Centre of Excellence, Winnipeg, MB. 
Lamouche, J 2002, Environmental scan of Métis health information, initiatives and programs, National Aboriginal Health Organization, Ottawa, ON.

Martens, P, Bartlett, J, Prior, H, Sanguins, J, Burchill, C \& Burland, E 2011, 'What is the comparative health status and associated risk factors for the Métis? A population-based study in Manitoba, Canada', BMC Public Health, vol. 11, p. 814.

McCabe, A \& Horsley, K 2008, The evaluator's cookbook, Routledge, New York.

McCloskey, D, McDonald, M, Cook, J, Roberts, S, Updegrove, S, Sampson, D, Gutter, S \& Eder, M 2011, 'Chapter 1, Community engagement: Defining and organizing concepts from the literature', in Principles of community engagement, 2nd edn, National Institutes of Health, USA, pp. 3-41.

McNab, D 2005, Walking a tightrope: Aboriginal people and their representations, Wilfred Laurier University Press, Waterloo, ON.

Minkler, M \& Wallerstein, N 2003, Community based participatory research for health, Jossey-Bass, San Francisco, CA.

Natural Sciences and Engineering Research Council of Canada 2013, Tri-Agency financial administration guide - Use of grant funds, viewed August 2013, www.nserc-crsng.gc.ca/Professors-Professeurs/ FinancialAdminGuide-GuideAdminFinancier/FundsUseUtilisationSubventions eng.asp.

Oetting, E, Jumper-Thurman, P, Plested, B, Edwards, R 2001, 'Community readiness and health services', Substance Use and Misuse, vol. 36, nos 6\&7, p. 825 .

Plested, B, Edwards, R \& Jumper-Thurman, P 2006, Community readiness: A handbook for successful change, Tri-Ethnic Center for Prevention Research, Fort Collins, CO.

Rath, T 2012, Strengthsfinder 2.0, Gallup, New York, NY.

Statistics Canada 2010, The health of Inuit, Métis and First Nations adults living off-reserve in Canada: The impact of socioeconomic status on inequalities in health, Health Research Working Paper Series, Ottawa, viewed August 2013, www.statcan.gc.ca/pub/82-622-x/2010004/fig/ Figure02-eng.htm.

Tjepkema, M, Wilkins, R, Senécal, S, Guimond, E \& Penney, C 2011, Potential years of life lost at ages 25 to 74 among Métis and Non-Status Indians, 1991 to 2001: Health report, March, Statistics Canada, Ottawa, ON.

Younge, T 2003, 'Review of research on Aboriginal populations in Canada: Relevance to their health needs', British Medical Journal, vol. 327, issue 7412, p. 419. 